\title{
Perception of airflow obstruction and associated breathlessness in normal and asthmatic subjects: correlation with anxiety and bronchodilator
} needs

Louis-Philippe Boulet, Isabelle Cournoyer, Francine Deschesnes, Pierre Leblanc, Arie Nouwen

\begin{abstract}
Background - Perception of bronchoconstriction varies between individuals and its determinants remain to be identified. The perception of airflow obstruction and breathlessness during induced bronchoconstriction was studied, and the effects of anxiety, repetition of the stimulus, and bronchodilator needs on these measurements were examined in normal and asthmatic subjects.
\end{abstract}

Methods - Fifteen normal (control) and $\mathbf{2 5}$ asthmatic subjects had two consecutive methacholine inhalation tests to induce a $20-50 \%$ fall in $\mathrm{FEV}_{1}$. Evaluation of the perceived magnitude of airflow obstruction, breathlessness, level of anxiety generated, and bronchodilator needs was obtained before each $F E V_{1}$ measurement on a modified Borg scale from 0 to 10 . Results - Mean (SE) maximal fall in FEV in asthmatic and control subjects was of similar magnitude: test $1,37.6(1.4) \%$ and $38.7(3 \cdot 1) \%$, and test $2,36 \cdot 0(1 \cdot 6) \%$ and $27 \cdot 7(2 \cdot 4) \%$ respectively. There was a large interindividual variation in perception of airflow obstruction and breathlessness but, although they were well correlated in asthmatic subjects, they were perceived differently by the control subjects. Perception of airflow obstruction was greater in asthmatic subjects. The level of anxiety and the bronchodilator use were low and did not influence perception.

Conclusions - During induced bronchoconstriction, the overall perception of airflow obstruction and breathlessness were similar among asthmatic subjects but controls showed a higher perception of airflow obstruction for any given level of breathlessness. Asthmatic subjects perceived airflow obstruction and breathlessness to a greater degree than did controls but anxiety and bronchodilator need were not correlated with respiratory sensation. The variability of bronchodilator use for similar degrees of bronchoconstriction suggests that it may be misleading to assess the severity of asthma control using only this indirect measure.

(Thorax 1994;49:965-970)
Perception and interpretation of physiological sensations vary from one subject to another. ${ }^{12}$ Somatic sensations such as breathlessness may be influenced by different factors including differences in integration of sensory sensations, personality, anxiety and temporal adaptation to repetition of the stimulus. ${ }^{3-5}$ Perception of nociceptive sensations, such as those following bronchoconstriction, show large interindividual variability and this can influence treatment as it is the level of unpleasant symptoms which determines medication needs. ${ }^{6-8}$ Poor perception of bronchoconstriction has been described previously and may influence asthma control. ${ }^{27-9}$ We have recently reported that perception of induced bronchoconstriction follows a normal distribution in a population of subjects with airway hyperresponsiveness. ${ }^{8}$

There is usually a direct correlation between breathlessness scores and fall in expiratory flows in asthma. ${ }^{281011}$ Although it is considered that affective and sensory sensations are correlated, clinical observations and recent reports suggest that perception of a similar change in pulmonary function may be associated with different degrees of nociceptive, or unpleasant sensations between individuals. Furthermore, different distinguishable types of dyspnoea may exist in the same individual. ${ }^{12}$

If there is a difference between perception of the physiological change and the resulting nociceptive sensation, this could lead to inappropriate or insufficient treatment. In a recent study of asthmatic patients in remission, we found subjects who clearly perceived falls in expiratory flow but had low perception of the associated sensation of breathlessness. ${ }^{13}$

This study aimed to explore the differences between the perception of induced bronchoconstriction and its associated nociceptive sensation, breathlessness, and to determine whether anxiety or the repetition of the stimulus changed the perception or bronchodilator needs.

\section{Methods}

SUBJECTS

Forty non-smokers (25 asthmatic subjects and 15 controls) were recruited from the Laval Hospital Asthma Clinic or from hospital staff (table). Of the asthmatic subjects 15 were men and 10 were women of mean age $24 \cdot 3(1 \cdot 0)$ years, and all fulfilled the American Thoracic

Unité de Recherche, Pneumologie de Respiratory Health Sainte-Foy, Québec,

L-P Boulet

P Deschesn
} 
Characteristics of subjects

\begin{tabular}{lcc}
\hline & $\begin{array}{l}\text { Asthmatic } \\
\text { subjects }\end{array}$ & $\begin{array}{l}\text { Normal } \\
\text { subjects }\end{array}$ \\
\hline Number of subjects & $25(15 \mathrm{~F} / 10 \mathrm{M})$ & $15(7 \mathrm{~F} / 8 \mathrm{M})$ \\
Mean (SE) age (years) & $24 \cdot 3(1 \cdot 0)$ & $26 \cdot 3(1 \cdot 6)$ \\
Mean (SE) baseline expiratory flows (\%) $_{\text {FEV }}$ & $90 \cdot 4(2 \cdot 9)$ & $97 \cdot 1(2 \cdot 9)$ \\
FVC & $101 \cdot 9(2 \cdot 6)$ & $100 \cdot 9(2 \cdot 2)$ \\
Range (geometric mean) PC $_{20}(\mathrm{mg} / \mathrm{ml})$ & $0 \cdot 12$ to $6 \cdot 4(1 \cdot 12)$ & $11 \cdot 3$ to $151 \cdot 0(53 \cdot 5)$ \\
$\quad$ st test & $0 \cdot 09$ to $8 \cdot 49(1 \cdot 09)$ & $-8 \cdot 0$ to $256 \cdot 0(52 \cdot 4)$ \\
2nd test & $16 \cdot 0(1 \cdot 7)$ & - \\
Mean (SE) duration of asthma (years) & 25 & - \\
Current medication & 11 & - \\
Inhaled $\beta_{2}$ agonist (as needed) & $636(100-1000)$ & \\
Inhaled beclomethasone & 3 & \\
Mean (range) daily dose $(\mu \mathrm{g})$ & $533(400-800)$ & \\
Inhaled budesonide & \multicolumn{2}{|c}{} \\
Mean (range) daily dose $(\mu \mathrm{g})$ &
\end{tabular}

Society criteria for asthma. ${ }^{14}$ Their asthma was mild to moderate and respiratory symptoms and medication were unchanged for at least one month. All used a $\beta_{2}$ agonist on demand, 14 subjects took an inhaled steroid in addition. $\beta_{2}$ agonist use was not formally recorded but on initial evaluation most patients used less than four inhalations per day. The control subjects comprised eight men and seven women of mean age $26.3(1.6)$ years. None had any history of asthma, and all had normal baseline forced expiratory flows and airway responsiveness (table). The provocative concentration of methacholine inducing a $20 \%$ fall in forced expiratory volume in one second $\left(\mathrm{PC}_{20} \mathrm{FEV}_{1}\right)$ was measurable $(<256 \mathrm{mg} / \mathrm{ml})$ in all subjects.

The study was approved by the Laval Hospital ethics committee and all subjects signed an informed consent form.

\section{STUDY DESIGN}

At the first visit each subject completed a respiratory questionnaire and recorded measurements of expiratory flows and airway responsiveness to methacholine according to the method of Juniper et al. ${ }^{15}$

Expiratory flows were measured with a Vitalograph PFT II using standard guidelines. ${ }^{16}$ Progressive concentrations of methacholine were inhaled until a $20-50 \%$ fall in $\mathrm{FEV}_{1}$ was achieved, to obtain a sufficient stimulus to allow a range of perception scores, without the airways obstruction becoming intolerable for the subject.

$\mathrm{FEV}_{1}$ was measured initially then every minute after the first methacholine inhalation. Before each $\mathrm{FEV}_{1}$ measurement the subject answered the following questions to which he was trained before the study: (1) How much do you think your airways have closed up (airflow obstruction)? (2) How short of breath are you presently; to what degree is your breathing uncomfortable (breathlessness)? (3) What is your level of anxiety now (anxiety)? (4) Do you feel the need to use your bronchodilator at this time, and if yes, how badly (bronchodilator need)?

Perception of airflow obstruction was defined as the sensation of a change in breathing pattern or the ability to breathe. Breathlessness was defined as the unpleasant sensation associated with bronchoconstriction. Current level of anxiety was characterised by subjective feelings of tension, apprehension, nervousness and worry, and by activation or arousal of the autonomic nervous system.

Each subject responded to these questions on two different perception scales: (1) a modified Borg scale where 0 was nothing and 10 maximum, and (2) on a visual analogue scale from $0 \mathrm{~cm}$ (no perception) to $20 \mathrm{~cm}$ (maximum). ${ }^{17}$ The visual analogue scale consisted of a horizontal $20 \mathrm{~cm}$ ruler without any mark on the patient's side. The subject had to indicate his perception by moving a marker along the ruler. There was no significant difference between mean perception scores on the Borg and visual analogue scale for any tests both in control or asthmatic subjects $(p>0.05)$. The Borg scale was used subsequently for comparisons between the different perception scores for each parameter studied, as well as for bronchodilator need assessment.

When the maximum fall in $\mathrm{FEV}_{1}$ was obtained $(50 \%$ or when symptoms were troublesome), the five previously described questions were then asked at five minute intervals over a period of 30 minutes. As soon as $\mathrm{FEV}_{1}$ returned to within $80 \%$ of initial baseline value a second methacholine inhalation test was repeated with the same measurements.

\section{DATA ANALYSIS}

To describe the relation between the fall in expiratory flow (independent variable) with the symptoms (airflow obstruction, breathlessness, and anxiety) and bronchodilator need (dependent variables) in asthmatic and control subjects a linear model of regression was used as well as an indicator variable ( 0 or 1$)$ to identify groups. Furthermore, we introduced a cross-product term into the regression model (product between the fall in expiratory flow and the indicator variable that identified groups) as we expected an interaction effect between these two independent variables. The same approach was used to compare perception of breathlessness during bronchoconstriction and recovery. The indicator variable was used to identify bronchoconstriction or recovery.

Mean values of quantitative variables were compared with the Student's paired $t$ test for comparison between initial and final methacholine inhalation test and with a Student's $t$ test for comparison between the two study 


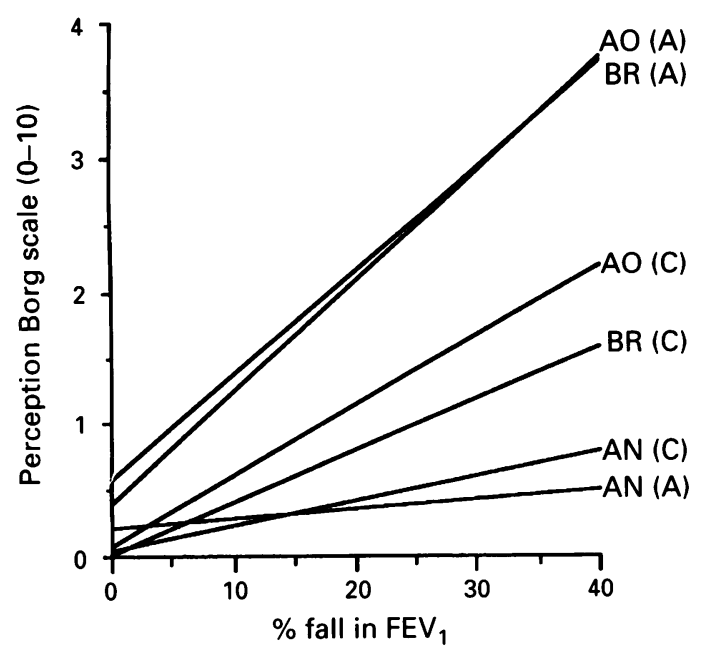

Figure 1 Relation between fall in expiratory flow and symptoms (airflow obstruction: $A O$, breathlessness: $B R$, anxiety: $A N)$ in asthmatic $(A)$ and control $(C)$ subjects. Perception scores of asthmatic subjects were higher for airflow obstruction $(p<0.01)$ and for breathlessness $(p<0 \cdot 01)$. Control subjects had higher scores for AO than $B R(p<0.05)$. Anxiety levels were generally low in both groups and unrelated to perception of $A O$ or $B R$.

groups. The Wilcoxon signed test and rank sum test were performed when the data were not normally distributed. All comparisons were two-tailed and were obtained with SAS software.

\section{Results}

EXPIRATORY FLOWS AND AIRWAY RESPONSIVENESS

Baseline $\mathrm{FEV}_{1}$ values in the asthmatic subjects ranged from $68 \%$ to $110 \%$ (mean: $90 \cdot 4 \%$ pre- dicted) and from $76 \%$ to $120 \%$ (mean $97 \cdot 1 \%$ ) in control subjects (table). Baseline FVC (percent predicted) was $84-136 \%$ (mean 102\%) for the asthmatic subjects and $85-121 \%$ (mean $101 \%$ ) for the non-asthmatic subjects. $\mathrm{PC}_{20}$ varied from 0.12 to $6.44 \mathrm{mg} / \mathrm{ml}$ (geometric mean (GM) 1.12) in asthmatic subjects and from 11.3 to $151 \mathrm{mg} / \mathrm{ml}(53.5)$ in control subjects. On the second methacholine inhalation test the $\mathrm{PC}_{20}$ in the asthmatic subjects was similar and the respective values in the two groups of subjects were $0.09-8.49 \mathrm{mg} / \mathrm{ml}$ (mean 1.09) and $8 \cdot 0-256 \mathrm{mg} / \mathrm{ml}$ (mean 52.4).

At the beginning of the second test all subjects had an $\mathrm{FEV}_{1}$ over $80 \%$ of baseline except one who had not recovered sufficiently to proceed to the second challenge test. The mean (SE) maximum fall in $\mathrm{FEV}_{1}$ after the first methacholine inhalation test was $37.6(1.4) \%$ for the asthmatic subjects and $38 \cdot 7(3 \cdot 1) \%$ for control subjects from baseline. On the second test the fall in $\mathrm{FEV}_{1}$ was $36 \cdot 0(1 \cdot 6) \%$ and $27 \cdot 7$ $(2 \cdot 4) \%$ respectively $(\mathrm{p}<0 \cdot 01)$.

\section{COMPARATIVE PERCEPTION OF CHANGES IN} EXPIRATORY FLOW, ASSOCIATED DISCOMFORT AND ANXIETY IN ASTHMATIC AND CONTROL SUBJECTS

There was considerable variability between subjects in the perception of the different variables evaluated, although in the asthmatic subjects scores were higher, whatever the percentage fall in $\mathrm{FEV}_{1}$, both for the perception of physiological stimulus $(p<0.01)$ or the associated discomfort (breathlessness) $(\mathrm{p}<0.01)$ (fig 1). Furthermore, as shown in fig 1 , this difference increased with the severity of

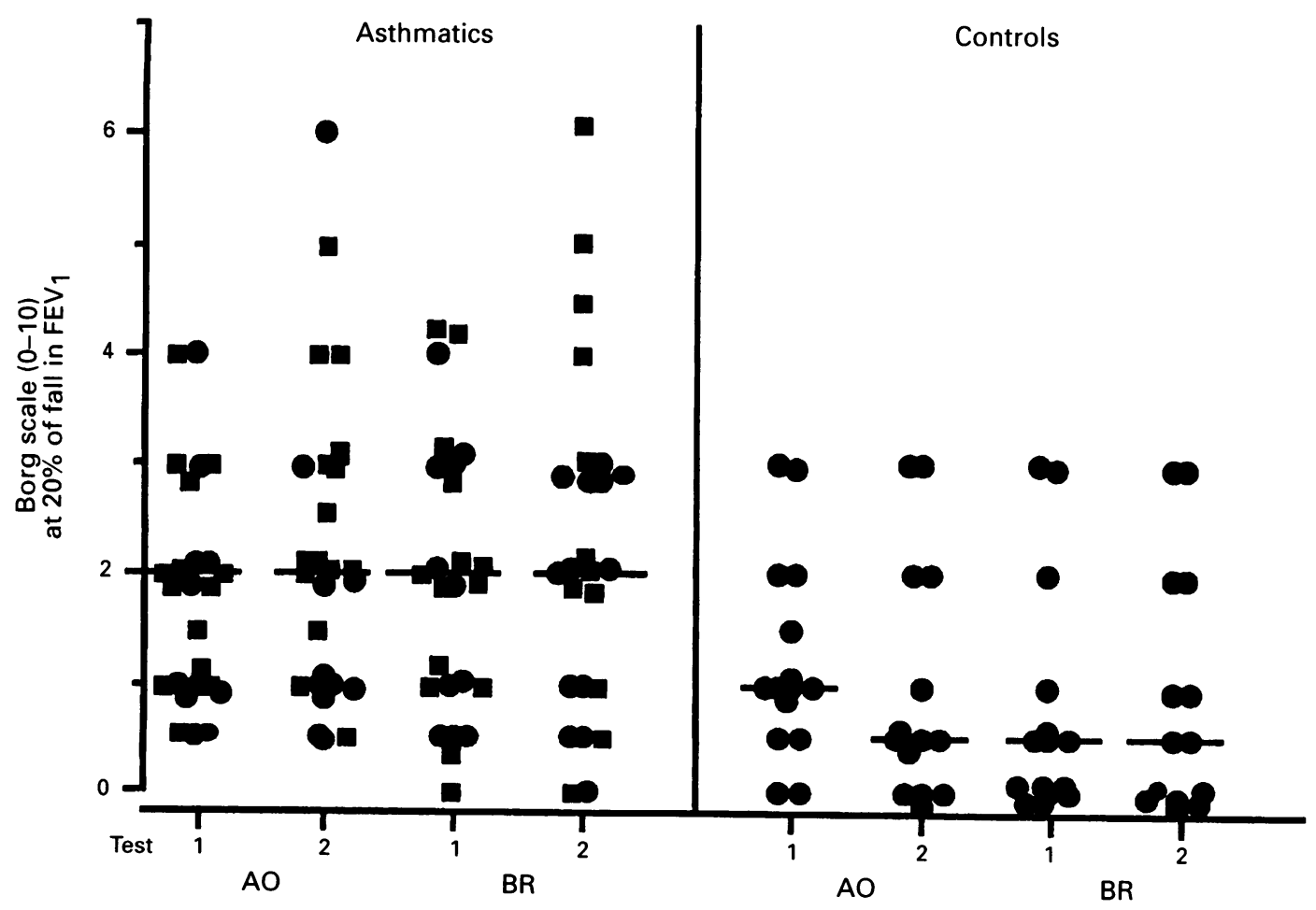

Figure 2 Comparative airflow obstruction (AO) and breathlessness $(B R)$ perception scores and the influence of repetition of bronchoconstriction on differential perception at $20 \%$ fall in FEV $V_{1}$. Median perception scores for the different parameters after initial and final methacholine inhalation tests were similar. Overall asthmatic subjects had a higher perception of $A O$ and $B R$ than controls: test $1: A O(p>0.05), B R(p<0.01)$; test $2: A O(p<0 \cdot 01), B R(p=0 \cdot 01)$.

$=$ patients using only $\beta_{2}$ agonist; $\square=$ patients using $\beta_{2}$ agonist and beclomethasone. 


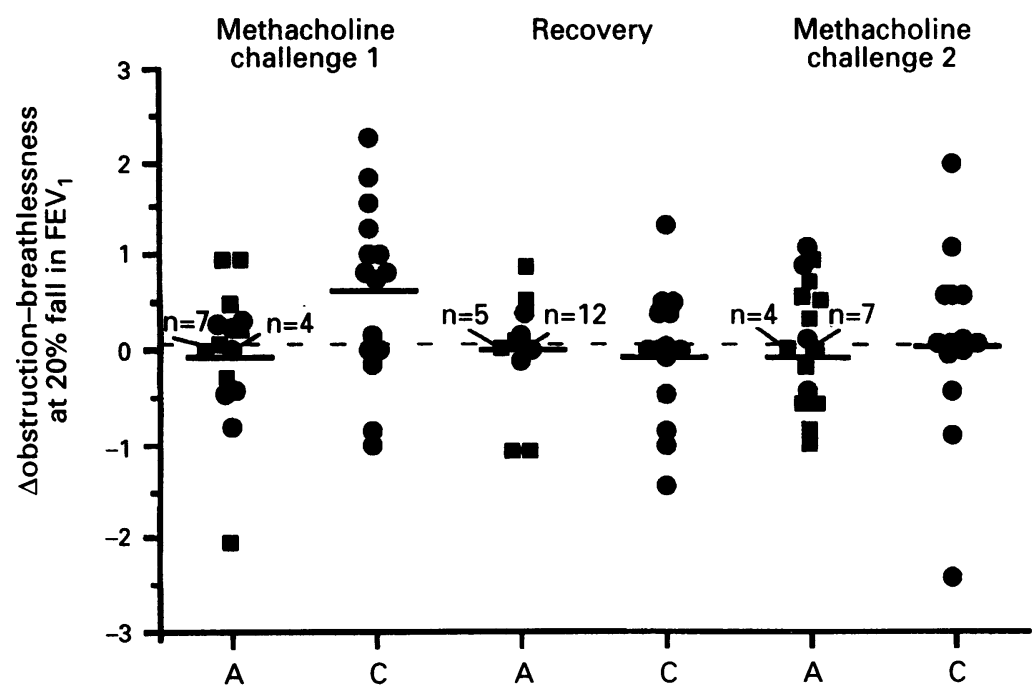

Figure 3 Difference in perception of airflow obstruction $(A O)$ and breathlessness $(B R)$ in the two study groups at $20 \%$ fall in FEV $V_{1}$. The perception of change in $A O$ compared with $B R$ was variable between subjects. During bronchoconstriction $A O-B R$ difference was higher in controls on test $1(p<0.05)$ but not on test $2(p>0.05)$. = patients using only $\beta_{2}$ agonist; $\square=$ patients using $\beta_{2}$ agonist and beclomethasone. $A=$ asthmatic group; $C=$ controls.

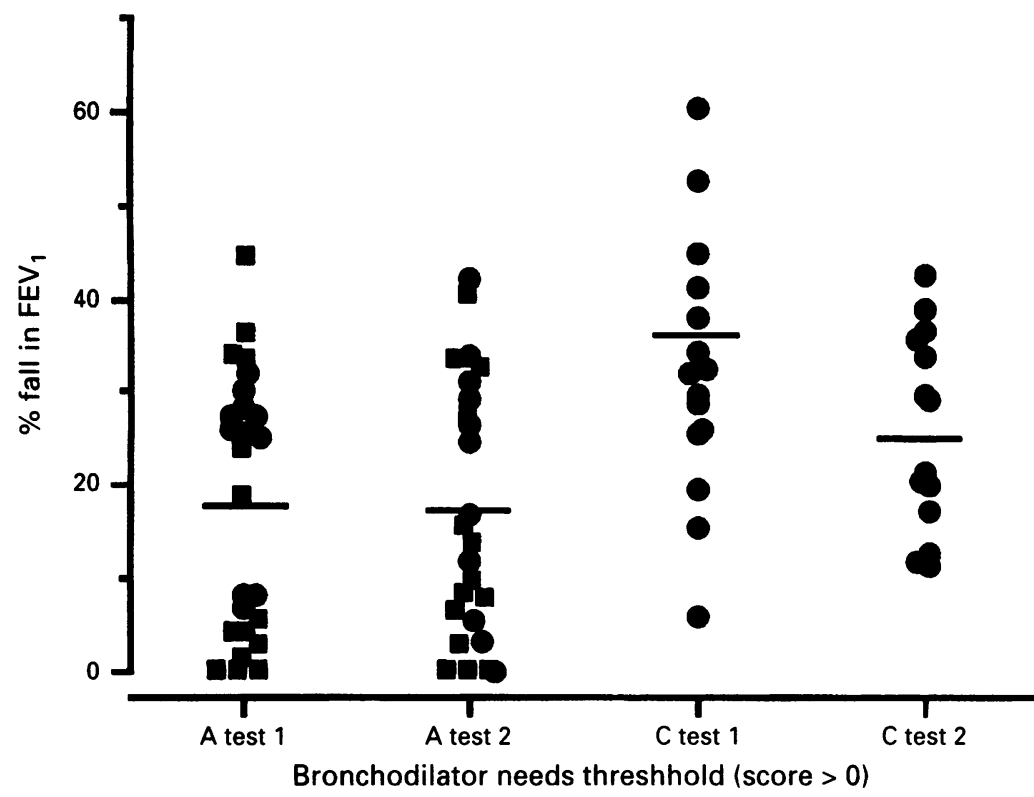

Figure 4 Bronchodilator needs in the two groups of subjects. These were lower in controls (C) than in asthmatic subjects $(A)$, particularly on the first test $(p<0.01) .0=$ patients using only $\beta_{2}$ agonist; $\square=$ patients using $\beta_{2}$ agonist and beclomethasone.

bronchoconstriction. The median scores for perception of airflow obstruction (AO) and breathlessness (BR) when $\mathrm{FEV}_{1}$ fell by $20 \%$ were $2 \cdot 0 / 2 \cdot 0$ in the asthmatic subjects and $1.0 / 0.5$ in the controls for test 1 (AO: $p>0.05$, BR: $p<0.01$ ) and $2.0 / 2.0$ in the asthmatic subjects and $0.5 / 0.5$ in the controls for test 2 (AO: p<0.01, BR: p<0.05) (fig 2).

In test 1 mean differences between airflow obstruction and breathlessness scores when the FEV $_{1}$ fell by $20 \%$ were $0.63(0.24)(p=0.02)$ in the control subjects and $-0.02(0.11)$ in the asthmatic subjects $(p>0.05)$. Twelve control and 20 asthmatic subjects had a mean AO higher than BR scores, with a respective mean score difference between perception of airflow obstruction and breathlessness of $0.96(0.20)$ and $0 \cdot 18(0 \cdot 07)$. Three control and five asthmatic subjects had a mean AO lower than
BR scores, $-0.67(0.26)$ and $-0.82(0.31)$, respectively (fig 3 ).

Anxiety levels were low in both groups and did not correlate with breathlessness or bronchodilator needs. In the asthmatic subjects, compared with control subjects, median scores of anxiety were 0 for tests 1 and $2(p>0.05)$ when the $\mathrm{FEV}_{1}$ fell by $20 \%$.

PERCEPTION OF PHYSIOLOGICAL CHANGE $v$ BREATHLESSNESS AND ANXIETY

After a $20 \%$ fall in $\mathrm{FEV}_{1}$ (fig 2) the perception of breathlessness compared with perception of the physiological change was similar among asthmatic subjects in test $1(\mathrm{p}>0.05)$. During bronchoconstriction the perception of changes in expiratory flow was higher than that of breathlessness in control subjects in test 1 $(p<0.05)$ but not in test $2(p>0.05)$. During recovery perception was similar in the two groups (fig 3). There was no significant correlation between anxiety scores and airflow obstruction, breathlessness, and bronchodilator need.

INFLUENCE OF REPETITION OF BRONCHOCONSTRICTION ON PERCEPTION There was no significant difference in perception of airway obstruction and breathlessness or anxiety (fig 2) between the initial and second methacholine inhalation test. Looking at a possible acute temporal adaptation, we found that mean perception scores for a similar fall in $\mathrm{FEV}_{1}$ were identical before the first and second $\mathrm{FEV}_{1}$ measurements performed at a one minute interval.

PERCEPTION OF BREATHLESSNESS ON INDUCTION OF BRONCHOCONSTRICTION COMPARED WITH RECOVERY

The slope of perception of breathlessness/percentage fall in FEV 1 was similar during induction and recovery for asthmatic subjects but was steeper in controls during induction of bronchoconstriction $(p<0.05)$. Although the overall perception of breathlessness was less on recovery, the mean perception at $20 \%$ fall in $\mathrm{FEV}_{1}$ on recovery compared with induction was similar in both groups $(p>0.05)$.

BRONCHODILATOR NEEDS IN RELATION TO FALL IN FEV

The perceived need for bronchodilator use was small in both groups of subjects but lower in the controls, particularly after the first methacholine inhalation test, and did not correlate with airflow obstruction, breathlessness, or anxiety scores. The respective mean (SE) percentage fall in $\mathrm{FEV}_{1}$ at which the subjects felt the need to use their bronchodilator was 17.6 (3.0)\% (asthmatics) and 34.0 (3.4)\% (controls) in test $1(\mathrm{p}<0.01)$; and 17.0 (2.9)\% (asthmatics) and $25.0(2.6) \%$ (controls) in test 2 $(p<0.01$ ) (fig 4). 


\section{Discussion}

We found that perception of airflow obstruction and associated breathlessness following methacholine induced bronchoconstriction was usually correlated, although some subjects, particularly non-asthmatics, had lower scores for breathlessness at a given perception score of airflow obstruction. Mean perception scores for airflow obstruction and breathlessness were also higher in asthmatic than control subjects. Anxiety levels and bronchodilator needs during induced bronchoconstriction were low and did not correlate with breathlessness.

Subjects could differentiate changes in airway calibre and breathlessness independently. Perception of a fall in expiratory flow and breathlessness were closely correlated in most individuals, although there was a range of differential perception between the two sensations. In some, a perceived change in pulmonary function was associated with significantly less discomfort. This has been found with other types of sensations, such as pain induced by pressure, where some tolerate a high level of pressure before complaining of pain, while others note pain on minimal pressure. ${ }^{18}$ Other observations also suggest a dissociation in some subjects between perception of physiological changes such as respiratory effort and dyspnoea, defined as an unpleasant urge to breathe. ${ }^{19}$ These differences may be related to the mechanisms involved in the perception of nociceptive stimuli at the central nervous system level, at the sensory afferent pathways, or to adaptation to a recurrent stimulus or other psychological factors such as anxiety. ${ }^{3-5}$ In the present study, however, neither anxiety nor repetition of the stimulus was related to perception of breathlessness.

Other determinants of perception, such as airflow obstruction or breathlessness, may be related to hyperventilation and also to anxiety. Although ventilation was not measured in this study, we have previously reported an increase in perception scores during resistive loaded breathing in asthmatic subjects, although they had significantly lower minute ventilation rates than controls. ${ }^{20}$ Furthermore, we and others have suggested a role for hyperinflation in the perception of acute bronchoconstriction. ${ }^{21} 22$

The observation that control subjects have lower levels of perception than asthmatic subjects is in keeping with our previous data and those of others, which showed that asthmatic subjects had higher perception scores when progressive increases in resistive loads were applied. ${ }^{2023}$ We may hypothesise that asthmatics are used to recognising this type of change in lung function or that other events such as methacholine-induced increase in lung volumes may be more severe in asthmatic subjects, although further studies are needed to verify this.

The nature and origin of anxiety is still an object of debate. ${ }^{24}$ In many psychophysiological studies, however, including the present one, state anxiety may be operationally defined to allow its measurement. The low level of anxiety we observed may be because some of our subjects had performed previous provocation tests and felt secure in the hospital surrounding. This may be different if bronchoconstriction occurred when they were alone, outside medical facilities, or if they had associated panicfear disorders or a high level of anxiety. ${ }^{25}$ The absence of correlation with anxiety is different from that reported by Zamary who showed that dyspnoea induced by hypercapnic stimulation correlated well with the level of anxiety generated by the test. ${ }^{26}$ This may be related to the magnitude or the nature of the stimulus. In our study, even with a fall in $\mathrm{FEV}_{1}$ of as much as $50 \%$, many subjects were not particularly uncomfortable.

Orehek et al suggested that chronic airflow obstruction causes a reduction in perception of change in bronchial tone. ${ }^{5}$ We have reported that perception of bronchoconstriction is related to its speed of onset, suggesting a temporal adaptation. ${ }^{27}$ However, we found no short term adaptation as the mean perception scores after the first and second methacholine inhalation tests were similar.

Another finding was the low level of bronchodilator requirement in both control and asthmatic groups. This may be related to the secure environment of the hospital, although we took care to ask the subjects to assess their bronchodilator needs as if they were not in a medical environment. This suggests that, in many individuals, it may take large changes in pulmonary function to create a need for medication. Bronchodilator need assessment may sometimes overestimate but, most importantly, underestimate the level of control of asthma. Again control subjects perceived less need than asthmatic subjects, possibly as they were less used to the relief produced by such treatment. Finally, the patients had mild to moderate asthma and these observations may differ in more severe patients or in those with more brittle asthma.

In conclusion, perception of bronchoconstriction and associated breathlessness varies between subjects and is not usually related to anxiety or bronchodilator needs, nor correlated to either of these parameters. Our group $^{28}$ and Ruffin et $a l^{9}$ have reported that the level of perception of induced breathlessness does not predict whether an asthmatic subject is at risk of a severe attack. However, identifying subjects with a low level of breathlessness who readily perceive physiological change (airflow obstruction) may be valuable. Furthermore, bronchodilator needs should be used with caution as a measure of asthma control, and is better measured in conjunction with objective measurements such as peak flow.

1 Burdon JGW, Juniper EF, Killian KJ, Hargreave FE, Campbell EJM. The perception of breathlessness in asthma. Am Rev Respir Dis 1982;126:825-8.

2 Côté J, Leblanc P, Boulet L-P. Perception of bronchospasm in control and asthmatic subjects. Am Rev Respir Dis 1987; 135:A231.

3 Altose MD. Dyspnea. In: Current pulmonology. Chicago: Year Book Publishers, 1986:199-226. 4 Barnes PJ. Poorly perceived asthma. Thorax 1992;47:408-9. Perception of airway tone by asthmatic patients. Bull Eur Physiopathol Respir 1982;18:601-7.

6 Palmer KNV, Kelman GR. Pulmonary function in asthmatic patients in remission. $B M \mathcal{F} 1975 ; 1: 485-6$. 
7 Rubinfeld AR, Pain MCF. Perception of asthma. Lancet 1976;i:882-4.

8 Turcotte H, Boulet L-P. Perception of induced bronchoconstriction as an index of awareness of respiratory symptoms. Chest 1994;105:1430-3.

9 Connolly MJ, Crowley JJ, Charan NB, Nielson CP, Vestal RE. Reduced subjective awareness of bronchoconstriction provoked by methacholine in elderly asthmatic and control subjects as measured on a simple awareness scale. Thorax subjects as measur

10 Turcotte H, Corbeil F, Boulet LP. Differential perception of bronchospasm after antigen, exercise and histamine of bronchospasm after antigen, exer

11 McFadden ER Jr, Kiser R, de Groot WJ. Acute bronchia asthma: relation between clinical and physiological manifestations. N Engl f Med 1973;288:221-5.

12 Simon PM, Schwartzstein RM, Weiss JW, Lahive K, Fencl $\mathrm{V}$, Teghtsoonian $\mathrm{M}$, et al. Distinguishable sensations of breathlessness induced in control volunteers. Am Rev Respir Dis 1989;140:1021-7.

13 Boulet L-P, Turcotte H, Brochu A. Persistence of airway obstruction and hyperresponsiveness in subjects with astiona remission. Chest 1994;105:1024-31.

14 American Thoracic Society. Standards for the diagnosis and care of patients with chronic obstructive pulmonary disease (COPD) and asthma. Am Rev Respir Dis 1987;136:225-44

15 Juniper E, Cockcroft DW, Hargreave FE. Histamine and methacholine inhalation tests: tidal breathing method - laboratory procedure and standardization. Canadian Thoracic Society. AB Draco, Lund, 1991.

16 American Thoracic Society Statement. Snowbird workshop in standardization of spirometry. Am Rev Respir Dis 1979; 119:831-8

17 Borg GAJ. Psychophysical bases of perceived exertion. Med Sci Sports Exerc 1982;14:377-81.
18 Hawley DJ, Wolfe F, Cathey MA. Pain, functional disability, and psychological status: a 12-month study of severity in fibromyalgia. $₹$ Rheumatol 1988;15:1551-6.

9 Demediuk BH, Manning H, Lilly J, Fencl V, Weinberger SE, Weiss JW, et al. Dissociation between dyspnea and respiratory effort. Am Rev Respir Dis 1992;146:1222-5.

20 Turcotte H, Tahan M, Leblanc P, Boulet L-P. Perception of acute or progressive resistive loads in normal and asthmatic subjects. Respiration 1993;60:203-11.

21 D'Amours P, Cormier Y, Boulet L-P, Leblanc P. Lung hyperinflation is a major determinant of dyspnea in hishyperinflation is a major determinant of dysp

22 Lougheed MD, Lam M, Forkert L, Webb KA, O'Donnell Lougheed MD, Lam M, Forkert L, Webb KA, O'Donnell
DE. Breathlessness during acute bronchoconstriction in asthma. Am Rev Respir Dis 1993;148:1452-9.

23 Burki NK, Mitchell K, Chaudhary BA, Zechman FW. The ability of asthmatics to detect added resistive loads. $A m$ Rev Respir Dis 1978;117:71-5.

24 Barlow DH. Anxiety and its disorders: the nature and treatment of anxiety and panic. New York: Guildford Press, 1988.

25 Lehrer PM, Isenberg S, Hockron SM. Asthma and emotion: a review. $\mathcal{F}$ Asthma 1993;30:5-21.

26 Zamary R, Kump K, Browner J, Redline S, Altose MD. Physiological and behavioral influences on hyperoxic hypercapnic ventilatory responses. Am Rev Respir Dis 1992, 145:A636.

27 Turcotte H, Boulet LP. Perception of early and late asthmatic responses following antigen challenge. $\mathcal{F}$ Allergy Clin Immunol 1991;27:S168.

28 Boulet LP, Deschesnes F, Gignac F, Turcotte H. Near fatal asthma; clinical and physiologic features, perception of bronchoconstriction and psychologic profile. $\mathcal{F}$ Allergy Clin Immunol 1991;88:838-46.

29 Ruffin RE, Laimer KM, Schembri DA. Longitudinal study of near fatal asthma. Chest 1991;99:77-83. 